\title{
One step forward, two steps back?
}

\section{The impact of the SAPS restructuring of the FCS Units}

\author{
CHERYL FRANK AND \\ SAMANTHA WATERHOUSE \\ cfrank@issafrica.org \\ sam@rapcan.org.za
}

In 2006, the South African Police Service underwent a massive restructuring aimed at eliminating the 'area' level (a functional level of services located between stations and the provincial level) and placing specially trained staff at provincial or station level. The FCS (family violence, child protection and sexual offences) units were among the services affected by this change. In 2007/08, RAPCAN (Resources Aimed at the Prevention of Child Abuse and Neglect) undertook a research project to review the impact of the change. The project included nine provincial workshops involving FCS staff and others, as well as a literature review of international trends. The study found that there is no longer a national pattern that demonstrates dedicated personnel and resources and specialised management of FCS cases. The study also found that South Africa is out of step with comparable poor and middle-income countries in effectively shifting away from specialised services. The study recommends that the SAPS implement a medium-term plan for the improvement of FCS services, with a focus on ensuring a continued increase in access to services, and a concomitant focus in ensuring the quality of these services.

The past five years have seen significant developments relating to the needs of crime victims in South Africa. These include the enactment of legislation such as the Children's Act, the Criminal Law (Sexual Offences and Related Matters) Amendment Act as well as two major policy processes relating to victims, i.e. the Service Charter for Victims of Crime, and the Victim Empowerment Programme (VEP). Therefore, the announcement that the SAPS was to restructure the family violence, child protection and sexual offences (FCS) services was accompanied by some bewilderment by civil society and government agencies alike.

Since the late 1980s detective services relating to sexual offences, family violence and child protection had seemed to be on a trajectory towards specialisation, starting with the introduction of the child protection units. The 2006 restructuring involved shifting a wide range of services that at the time were situated at 'area' level, either downwards to station level or to the provincial level. This had a profound effect on the FCS units, which were located at area level. The restructuring process resulted in the disbandment of the units and staff were sent to operate at station or 'cluster' level. SAPS management argued that the rationale for the move was that access to services would be increased. ${ }^{3}$

Civil society commentators acknowledged the positive intentions behind the SAPS plan, but 
questioned the implications of the move and raised concerns about the impact of the restructuring on the quality of service delivery to victims. Several themes dominated the statements of concern made by civil society commentators in response to the restructuring. These included that specially trained FCS detectives would now be utilised for the investigation of other cases; that victims would be exposed to secondary trauma if their cases were handled by personnel that did not have appropriate training or experience; and that the new managers of FCS detectives at station level would be unequipped to provide specialised management and direction to their staff. ${ }^{4}$

To address the lack of information about the actual impact of the restructuring, RAPCAN undertook research in 2007/08 to assess it. The results are detailed in the report entitled Raising the Bar: A review of the restructuring of the SAPS family violence, child protection and sexual offences units. ${ }^{5}$ This article presents a summary of the findings and recommendations from that study.

\section{THE SAPS FCS UNITS}

The FCS units were the end result of developments that started in the late 1980s and initially resulted in the establishment of child protection units, whose mandate was to address matters relating to child protection both of a criminal and non-criminal nature. In 1995, the mandate of these units was broadened to include certain crimes relating to adults, such as domestic violence and sexual offences. From this broader mandate the FCS units emerged; however, by 2006 when the SAPS announced the restructuring plan, a mix of FCS units and child protection units existed, and there were widely differing interpretations of the service mandates of these units.

Since 1995 the development of the FCS units reflected an approach towards specialisation, including dedicated human resources, specialised training, dedicated resources and infrastructure (such as buildings, vehicles, communications infrastructure and administrative capacity), and specialised management. An analysis of the budget shows that in the 2002/03 financial year, the SAPS allocated increased resources to improving FCS units, which is evidence of an intention to strengthen those services at the time. ${ }^{6}$ This was in line with other developments nationally that were aimed at attending to the rights and needs of crime victims. Greater specialisation in the investigation of the criminal matters addressed by these units was matched with concomitant developments in other parts of the criminal justice system, most notably in the prosecution service and the court system.

\section{THE RAPCAN STUDY}

The RAPCAN study sought to assess the impact of the restructuring on services to victims, and to review these developments in the context of international trends.

\section{Purpose and methodology}

The study sought to gather information as to the functionality of the FCS services both before and after the SAPS restructuring process. The central question addressed was whether the restructuring had taken South Africa closer to its objectives of improving services to victims, or whether it has resulted in a weakening of these services. While much of the SAPS communication relating to the restructuring emphasised that it was aimed at increasing access to these services, civil society commentators raised questions relating to the quality of these services. These two themes became central to questions addressed by the study. The study also sought to develop a baseline in terms of what should be defined as a high-quality service in relation to FCS services. It was believed that this would be important in order to have something to measure current and future services against. In addition, the research sought to reflect South African developments in an international context. 
A workshop was held in each province to build a picture of the status of FCS services since the restructuring, and to identify the central strengths and weaknesses of services both before and after the restructuring. The workshops included FCS and other SAPS personnel, government departments providing related services, and civil society organisations. The workshops also obtained the views of participants on what high-quality FCS services should look like and how the quality of these services should be monitored.

An extensive literature review was conducted, which provided data on how such services are conducted in comparable countries, with a view to assessing SAPS policy in the context of international developments and trends.

\section{FINDINGS FROM THE PROVINCIAL WORKSHOPS}

The decision taken by the SAPS to restructure its FCS units and redeploy personnel to cluster and station level had a profound effect on the nature of services delivered to victims, as well as on the personnel that provide these services.

Generally, the findings reflect that the trajectory towards increased specialisation in FCS cases that was apparent before the restructuring has been reversed by the decision to restructure. There are no longer dedicated officers, dedicated resources, and specialised management for cases within the FCS mandate. This was not the intention of the restructuring process, which was aimed at ensuring that, by placing specialist staff at station level, specialised services would be more accessible.

\section{Before the restructuring}

The service consisted of a mix of FCS and child protection units with varying approaches to addressing the full mandate of the units. Units served relatively small, primarily urban sections of the country, although some rural areas also received services. Services focused only on cases within the FCS mandate. Units in some provinces acted only in relation to parts of the mandate. The full FCS investigative mandate includes serious domestic violence-related offences of assault with the intention to cause serious bodily harm and attempted murder, ${ }^{7}$ all child protection matters (including criminal and non-criminal matters) and sexual offences against adults.

Over time the services offered by the FCS units became increasingly sophisticated, for example through the introduction of forensic social workers in provinces such as the Western Cape and North West.

FCS officers were specifically selected for the job, and most often also received specialised training. FCS officers actively applied to work in the units after making the decision to specialise in this area of investigation. Officers could therefore plan career paths within the specialised units. Officers were managed and supervised by detectives who often had significant experience in the investigation of FCS cases. There was generally a high level of commitment to the job, notwithstanding high levels of job stress and some resource constraints.

Some provinces seemed to be vastly more resourced than others in terms of numbers of personnel, as well as the nature of personnel available (e.g. the Western Cape). Units also had dedicated resources. These included office premises that were separate from the SAPS stations, vehicles, appropriate rooms for the interviewing of victims, and communications infrastructure (i.e. telephones, cell phones, Internet access, computers and administrative staff).

FCS units were allocated budgets that were managed in terms of their needs and priorities. This included funds to support overtime work.

\section{After the restructuring}

The nature of services to victims of domestic abuse, child abuse and sexual offences that would 
have fallen within the mandate of the FCS units, continues to be varied across the country. Services have been extended into some new rural areas, as was intended by the restructuring. However, in some cases this seems to have been at the expense of areas that were previously serviced. The new cluster-level system has resulted in detectives covering smaller geographical areas than was previously the case. This can improve investigations into cases in that area, but result in weakened investigations into cases falling outside the new boundaries.

Inter-sectoral relationships with other organisations assisting in the delivery of services were reported to have been seriously disrupted and, in one case, to have collapsed due to the restructuring.

Officers in provinces such as North West and Mpumalanga reported that they were now required to investigate other matters and were no longer dedicated to the investigation of FCS cases.

New FCS officers brought into the system since the restructuring did not seem to have undergone specific selection or screening processes such as psychometric tests. It would appear that these officers have been deployed into FCS work without specifically choosing this area of work. New officers were not given specific FCS training, although some may have received detective training. Some newly deployed staff in the Northern Cape did not have drivers' licences. The statement-taking skills of new officers were raised as a problem in KwaZulu-Natal and North West.

FCS officers are managed and supervised by heads of detectives at station or cluster level, except in the Western Cape. Reportedly, few of these heads have a clear understanding of the process of investigation of FCS cases.

Due to the restructuring, officers in four provinces (Eastern Cape, Gauteng, North West and Mpumalanga) reported levels of uncertainty, demoralisation and apathy.
Generally, resources allocated to the specialised units were devolved to station and cluster level, although there are some exceptions, e.g. the Port Elizabeth area and the Western Cape, where resources dedicated to the delivery of FCSrelated services have been maintained (at the time the data was collected). Some provinces reported that vehicles, telephones and computers are no longer dedicated to, or in some areas even available for FCS work and are being used by general detectives at stations. Reportedly this has had a profound impact on the ability to investigate matters, as detectives in this situation can no longer make contact with witnesses or access vehicles for collecting evidence or transporting witnesses to court.

Generally, FCS services no longer have dedicated facilities for working with victims. In new areas specialised resources such as victim-friendly rooms are not available. Where FCS services are still located in premises that previously housed FCS units, some special facilities are still available (e.g. in the Eastern Cape). Generally services are delivered out of SAPS stations, and not facilities that are appropriate for victims. Detectives in a number of stations in different provinces reported being expected to interview witnesses in offices shared by several other detectives.

FCS services no longer have their own associated budgets. Stations and clusters could not explain how services were to be funded, nor how resourcing should be motivated.

\section{FINDINGS FROM THE REVIEW OF INTERNATIONAL TRENDS}

The study sought to contextualise policy developments in South Africa within international trends as regards policing services for FCS crimes. Three types of situations were distinguished for analysis: poor and middleincome countries with specialised services, richer countries with specialised services, and countries without specialisation. The most critical part of the literature review was the identification of 
countries similar to South Africa in terms of income, size, population, challenges or some other factor (e.g. post-apartheid or post-conflict conditions) and then assessing the arrangements made in these countries in relation to the crime categories under review. Given the three types of situations that were examined, much was learnt from comparisons involving 20 countries (ten per cent of the world's states), managing thousands of police stations. Services in each country were studied in relation to organisation and management, collaboration, success rates, training, and resources.

\section{Poor and middle-income countries with specialised policing services}

Ten countries were reviewed: India, Malaysia, Nepal, Liberia, Mozambique, Mauritius, Namibia, Argentina, Brazil and Chile.

In all these countries services for FCS-type cases are located at district level. One of the reasons given for why poor and middle-income countries deliver services at district level is that they have fewer resources than rich countries, and fewer professionals available at local level to manage services. Under these conditions it makes more sense to offer good services at district level rather than offer many poorly run services at station level. South Africa does not fit the described pattern of district-level delivery, even though in terms of many other factors it fits the general profile of the middle-income countries like Argentina, Chile, Malaysia or Mauritius.

In nine out of ten of the poor and middle-income countries reviewed there was an integrated national plan for addressing the crimes concerned (often relating to both prevention and responsive services) with significant national oversight and management. India, which like the United States or Canada has large autonomous states that each organises its own services, was the exception. This was shown to result in inconsistent and less effective delivery, as there was no national-level group to monitor and evaluate.
National oversight accounted for successes both in poor countries like Nepal, and middle-income ones like Chile and Malaysia. In Chile there was something exceptional: a ministry at national level devoted not just to these investigations (monitoring and directing the detective work on women and children's issues), but with a mission to eradicate serious crime problems. Much evidence emerged to indicate that in poor and middle-income countries, a national department for issues such as those relating to women and children offered many advantages in terms of improved service delivery, over decentralised delivery.

All-female police stations are proliferating rapidly around the world in poor and middle-income countries (Nepal, India, Philippines, Pakistan, Peru, Colombia, Nicaragua, Brazil, Ecuador, Uruguay, Liberia and elsewhere), but no example of this was found in the richer countries. These stations can be within or part of regular stations (e.g. Brazil) but are sometimes entirely different facilities for the express purpose of handling specific cases more sensitively (e.g. Tamil Nadu). This dramatically increases resources since entire stations are then devoted to responding to the problem. Women police stations work for two main reasons: firstly, most women beaten or abused by men or who have had their children hurt by them are reluctant to report to male officers in male dominated stations who are not always sympathetic; and secondly women seem to make better and more sensitive investigators of crimes against women and children. There is empirical evidence to support this:

- Reporting levels doubled in Brazil and India when all-women police stations were established

- In India women started pouring in to report crimes from earlier years when they were too intimidated to report to male officers

- Women police detectives took such a strong interest that the investigation of such crimes increased dramatically

A number of governments, perceiving that these detective services were successful, invested in 
specialised units to the extent that they

proliferated around the world.

Police in both Chile and Argentina are mandated to respond to calls within minutes of a report of child abuse or domestic violence. Argentina is experimenting with mobile domestic violence units with two police members ready to arrest the perpetrator along with a psychologist and a social worker to support the victim. They are expected to arrive within 20 minutes of the call for assistance. There is good grounds for a speedy approach: one reason for low reporting rates for domestic violence and child abuse is that much time may pass between an incident and the victim being able to report it; during which the perpetrator pleads for forgiveness or threatens the victim.

Tamil Nadu has mobile units for a different reason, one that might also apply to South Africa: to reach rural areas with professional teams. A police officer, an advocate, a doctor, a social worker and a revenue department official work together to identify and resolve the problems on the spot.

There was evidence that both poor and middleincome countries (Malaysia, Mauritius, Argentina and Chile) showed similar trends: the creation of interdisciplinary teams that include detectives, psychologists, doctors, prosecutors, NGOs and other health practitioners, and integrated, monitored and evaluated national plans that concentrate the resources of various departments on the problem.

It seems, however, that the provision of police services to victims is not an adequate strategy for reducing crime levels. In no example was there clear evidence that these units prevent crimes against women and children. Even the best combination of services in Chile; accessible courts, researchers, national campaigns, trained judiciary, shelters, bringing offenders to book, and reintegrating victims of violence into their families, did not impact greatly on crime rates.

There was much evidence of success with regard to increased reporting levels, crime solving rates and victim satisfaction. However, conviction rates in all ten countries reviewed were relatively low.

Some of the countries reviewed set high standards in relation to the qualifications of the personnel working in the system. While Malaysia is very similar to South Africa in economic terms, the 110 women police investigators assigned to Malaysia's sexual abuse and child investigations division are required to have tertiary degrees in a relevant subject prior to police training.

It seems that training should not be considered a once-off event but take place on an ongoing basis to cover various aspects of investigations, the law and appropriate treatment of victims. In richer countries this is achieved with specialised units that do nothing else but provide this in accordance with evaluation results that determine exactly what these training needs are. This seems like good practice, but among the ten countries was found to occur only in Chile.

Many of the specialised units reviewed had their own budgets and resources. Brazil, Argentina and India have special women's police stations with their own budgets, teams of lawyers, psychologists and social workers to address these issues.

Likewise, Chile has a national department with entire institutes directed at the joint provision of psychological, legal, social and police services to woman and child victims. The notable exception to this trend was Namibia, where the women and child units struggle to obtain (and even compete to obtain) resources like vehicles that are needed to sustain routine daily activities.

\section{No specialisation within the police}

Five developing nations without specialised policing services were reviewed. These were Japan, Peru, Angola, Botswana and Turkey.

The most important finding in these countries is that the lack of specialisation had more to do with socio-cultural factors rather than a policy choice driven by objective studies or even economic considerations. These factors exist across the 
economic spectrum as they occur in rich (Japan), middle-income (Botswana, Turkey) and poor countries (Peru, Liberia) alike.

Violence against women and children is at such high levels in these countries that at the very least an integrated national plan is required to make headway against the problem. And disturbingly, violence against women and children can spiral so far out of control if not checked by an integrated response that includes police that it can affect more than 90 per cent of the population (e.g. Angola).

The enormity of the problem also leads to the conclusion that specially trained police units or even female police units would initially be more effective than trying to reform an entire police force deeply affected by a culture of patriarchy (for instance Angola's police force that is made up of male ex-combatants).

\section{Specialised services in richer nations}

The services in rich countries under review were so decentralised that much could be written just about specialised police services to victims of sexual offences and domestic violence in thousands of cities and towns. To condense this vast literature, only very general trends can be examined in five countries: Australia, Canada, New Zealand, United Kingdom, and the United States, involving 20 towns, cities and provinces. Some of the more significant trends in the wealthier countries include:

- Services decentralised to municipal or state level but with central offices that monitor and evaluate programmes, establish strategy and offer training

- Inter-departmental strategies offering a huge range of services and referrals according to joint protocols

- Professionals with tertiary qualifications providing high levels of specialised services including risk assessment

- Constant training prescribed by monitoring and evaluation units
- Rapid response teams offering mobile, holistic and integrated family services

- Intensive case management of both the victim and perpetrator for prevention

- Help desks, support services and emergency numbers that are advertised.

\section{KEY CONCLUSIONS}

The study came to the following conclusions:

The current system of delivery of FCS services represents a reversal in historical developments in South Africa that were aimed at offering a skilled, specialised service to complainants in FCS-related cases, premised on dedicated resourcing, specialised training and specialised management.

The current structure for the provision of FCS services is unable to offer dedicated resourcing, continued specialisation of officers nationally, and specialised management and oversight of FCS cases.

The policy objective to prioritise crimes against women and children cannot be realised under the current structure.

The current situation represents an absence of political will in government, and in the SAPS, in relation to the prioritisation of victims, especially in terms of crimes against women and children. Services have been devolved to local level without an articulated national strategy, specialised management and oversight, and dedicated budgets and resources.

The decision by the SAPS to devolve all area level services to cluster and station level did not take adequate account of the nature of FCS services, and the impact of the restructuring on the quality of services.

The process of restructuring in 2006 (which affected all the provinces except the Western Cape) resulted in confusion and uncertainty both internally in the SAPS and externally among civil society organisations, other government service providers and the general public, due to 
significant weaknesses in SAPS communications. This effect was felt also in the Western Cape where no restructuring took place during that period.

The restructuring resulted in the placement of FCS staff in service delivery positions. Many of these staff members: 1) were not suitably trained, 2) were not suitably experienced, 3) did not undergo special screening or selection, 4) had not specifically elected to work on FCS cases, and 5) did not have some of the basic requirements to undertake the job, e.g. drivers' licences.

The process of restructuring, which included the redeployment of existing FCS personnel, resulted in the demoralisation and demotivation of FCS officers.

The restructuring, although accompanied by some increase in access to services, resulted in a weakening of the quality of services provided nationally.

South Africa is out of step with comparable poor and middle-income countries in the world in effectively shifting away from specialised services.

The South African government is out of step with developments in some comparable countries that have demonstrated significant political leadership in responding to crimes against women and children.

South Africa is also out of step with comparable countries in relation to the creativity applied to addressing some of the crime problems within the FCS mandate.

Inter-sectoral collaboration with stakeholders that is required to deliver essential services to victims, has suffered due to the restructuring.

Victims have been negatively affected through the process of the restructuring and are currently exposed to services of questionable quality in many areas.

The current approach to measuring the effectiveness of services needs to be reviewed, to assess whether there has been a reduction in reporting.

\section{RECOMMENDATIONS OF THE STUDY}

The government as a whole needs to provide political and strategic leadership in order to respond more effectively to victimisation.

The SAPS needs to recognise that its restructuring plans were flawed, specifically in relation to their impact on FCS services, and accept that remedial actions will need to be taken. This is necessary to restore public confidence in the SAPS, and particularly in its commitment to prioritising crimes against women and children.

The SAPS needs to undertake a revision of the current structure for the delivery of FCS services. The focus should be on ensuring a continued increase in access to services, with a concomitant focus in ensuring the quality of these services. In all likelihood, this will require a shift away from station and cluster-level management to a more centralised management of the service, notwithstanding the location of the service at a more local level.

The SAPS should develop and publicise a national plan for the delivery of this service, adopting a short to medium-term orientation. This is also necessary for the restoration of public confidence in the SAPS's commitment to serving victims. This plan should set out a strategy for the achievement of high-quality services at an increasingly broader scale.

The requirements of such a plan and planning process are as follows:

- The plan should reflect the SAPS prioritisation of the FCS mandate and demonstrate commitment to its implementation through budgets and oversight measures.

- There should be processes at provincial level for consultation with civil society 
organisations and other government partners prior to the plan being finalised. One of the objectives of this should be to establish systems for ongoing communication and cooperation with civil society organisations, including their involvement in monitoring FCS services.

- Consultations with the public should be held in all provinces.

- The plan should map the current demand for services based on crime reporting nationally, as well as the current situation in relation to specialised personnel, budgets and resourcing for such services.

- The plan should demonstrate a strategy and budget to incrementally increase access to the service nationally.

- This should be accompanied by plans for the selection and training of personnel, and budgets for this.

- The plan should include standards in terms of resourcing to all FCS services, and an incremental strategy for the provision of these resources (with accompanying budgets).

- A structure and strategy for monitoring the quality of services nationally should be included. This should include the utilisation of indicators that are established through consultation with the public and civil society organisations.

- The plan must include a process for regular (at least annual) reporting to the public on the achievement of objectives.

\section{CONCLUSION}

The developments described in this study indicate the clear lack of coherence in policy between policing, prosecution and other justice services in relation to crime victims. If South Africa is to respond effectively to crime victimisation, much needs to be done to harmonise the actions and approaches of the government departments involved. The findings of this study place clear obligations on the SAPS to provide a coherent plan for the future of these services, and public confidence in the SAPS will depend on its ability to do so with both speed and integrity.

To comment on this article visit http://www.issafrica.org/sacq.php

\section{NOTES}

1 For a full analysis of these policy documents, see C Frank, Quality Services Guaranteed: A review of victim policy in South Africa, ISS Monograph 137, Institute for Security Studies, Pretoria, 2007.

2 A cluster consists of several police stations, with one of these acting as an administrative hub for the stations in the cluster.

3 C Frank, S Waterhouse, R Griggs and R Rontsch, Raising the Bar: A review of the restructuring of the SAPS family violence, child protection and sexual offences units, RAPCAN, 2008, 2.

4 Ibid, 3.

5 Ibid.

6 S Waterhouse and N Mazwayi, The Department of Safety and Security, in Parenzee (ed) Investigating the Implications of Ten Years of Democracy for Women: What do the budgets say? Idasa, 2005, 79.

7 Common assault and other offences considered less serious when committed in the context of domestic violence are investigated by the general detective services and not specialised detectives. 